\title{
Determination of Antioxidant 264 in the Butyl Rubber Stopper and the Compatibility with Recombinant Potent Antitumor and Antivirus Protein Injection
}

\author{
Min Zhao, ${ }^{1}$ Xianhui Li, ${ }^{1}$ Di Zhang, ${ }^{2}$ and Longshan Zhao ${ }^{1}{ }^{1}$ \\ ${ }^{1}$ School of Pharmacy, Shenyang Pharmaceutical University, Shenyang 110016, China \\ ${ }^{2}$ Shenyang Wellwolf Pharmaceutical Science and Technology Co. Ltd., Shenyang 110022, China \\ Correspondence should be addressed to Longshan Zhao; longshanzhao@163.com
}

Received 29 May 2020; Revised 25 July 2020; Accepted 26 August 2020; Published 9 September 2020

Academic Editor: Josep Esteve Romero

Copyright (c) 2020 Min Zhao et al. This is an open access article distributed under the Creative Commons Attribution License, which permits unrestricted use, distribution, and reproduction in any medium, provided the original work is properly cited.

Objective. To establish a method for extraction and determination of antioxidant 264 (2,6-di-tert-butyl-4-methylphenol) in the brominated butyl rubber stopper for injection and migration study in recombinant potent antitumor and antivirus protein injection (Novaferon). Methods. Dichloromethane-ethanol was adopted as the extraction solvent during the process of reflux extraction of antioxidant 264 in the brominated butyl rubber stopper. High-performance liquid chromatography (HPLC) was used for the determination of the migration of antioxidant 264 to Novaferon. The mobile phase consisted of acetonitrile-water $(80: 20, \mathrm{v} / \mathrm{v})$. The flow rate was $1.5 \mathrm{~mL} / \mathrm{min}$. The detection wavelength was $280 \mathrm{~nm}$. Results. The linearity range was from 4.003 to $200.150 \mu \mathrm{g} / \mathrm{mL}\left(r^{2}=0.99996\right)$, and the average recovery of antioxidant 264 was $97.8 \%$. The applicability of the methodology was good, which can be used for the determination of antioxidant 264. The results indicated that antioxidant 264 was not detected in Novaferon after the accelerated test and three months of long-term test. Conclusion. The established validated method in this study can be used for the determination of antioxidant 264 in the rubber stopper, and the brominated butyl rubber stopper has good compatibility with Novaferon.

\section{Introduction}

The efficacy and quality of drugs are closely related to human health and safety. The substance which consisted of internal medicine and packaging material of the direct contact drug is called medicine $[1,2]$. Packaging materials have been crucial components for drug products. Drug manufacturers use antioxidants, plasticizers, accelerators, and activators in order to achieve the required performance of their products. Consequently, the quality of the packaging material might have various negative effects on the pharmaceutical products and also be harmful to the human body $[3,4]$. The package of pharmaceutical products should be suitable for the standard of clinic and should have the following characteristics: protection, compatibility, safety, and functionality. A number of literature studies have reported the compatibility of pharmaceutical packaging [5-9]. The research of compatibility should include the interaction of packaging materials and drugs [10]. Compatibility studies demonstrate that there is no serious interaction between the packaging material and drugs. It is an objective requirement for the improvement of the inspection standard $[11,12]$. Therefore, the compatibility research of drugs and packaging materials should be carried out in the early stage of drug development or the selection of packaging materials throughout the entire process of drug development [13].

When selecting and confirming the packing seals, the pharmaceutical-producing enterprises should protect the quality of drugs and achieve the purpose of drug delivery in the process of packaging, storage, and transportation. Rubber is a kind of linear flexible macromolecule polymer. Its molecular chain is flexible and can produce large deformation under the external force. It can quickly restore its original shape when external force disappears [7]. Rubber is characterized by its excellent elasticity 
over a wide temperature range. As a packaging component, on the one hand, the rubber stopper should satisfy the sealing requirements of the packaging system; on the other hand, it should also have good compatibility with the drug, and it cannot be introduced into the safety risk of the extract, or the level of extract meets the safety requirements; the quality, efficacy, and safety of the drug will not be influenced by adsorption of active ingredients in pharmaceuticals or functional accessories [14-16]. Pharmaceutical manufacturers should assess potential safety risks and make corresponding compatibility studies based on the dosage form of the drug and the degree of risk of the route of administration. Compatibility test of the drug-packaging material and drugs refers to an experiment to investigate whether there is transfer or adsorption between drug-packaging materials and drugs, which can affect the quality of drugs $[17,18]$. The compatibility research of pharmaceuticals and packaging materials mainly includes three aspects: extraction study, interaction study (including migration test and adsorption test), and safety assessment [19].

Antioxidant 264 (2,6-di-tert-butyl-4-methylphenol) is an excellent generic phenolic antioxidant, which is most widely used as an antioxidant in plastics. It has the advantages of good antioxidant effect, high thermal stability, good compatibility with plastics, nonpollution to plastics, and so on $[20,21]$. The European Pharmacopoeia also regulates that the maximum amount of the antioxidant in pharmaceutical packaging is $0.3 \%$ [22]. Meanwhile, antioxidant 264 has the effect of inhibiting the activity of the human respiratory enzyme and increasing the activity of liver microsomes [23, 24]. The FDA Cancer Evaluation Committee is also considering the carcinogenicity of antioxidant 264 [25]. As rubber stoppers have the advantages of simple production process, abundant raw material sources, and high rate of quantity and price [26], Wang et al. identified that it is very important to determine the content of antioxidant 264 in rubber stoppers. Pu et al. established a method to determine antioxidant 1010 and antioxidant 5057 , which provided a reference for the detection of antioxidant migration [27]. Novaferon is based on 12 kinds of the IFN $\alpha$ gene (interferon alpha gene), which is a way to use DNA reorganization technology development of genetic engineering drugs [28], and the compatibility research between antioxidant 264 in rubber stoppers and Novaferon can better guarantee the safety, efficacy, and stability of the drug.

Based on the necessity of the aforementioned control of antioxidant 264, this study established a reflux extraction method of organic solvents to extract antioxidant 264 and determine it by HPLC. The method was simple and accurate for the determination of antioxidant 264 in brominated butyl rubber stoppers. Then, the developed method was successfully applied to the compatibility between brominated butyl rubber stopper and Novaferon to evaluate the safety of migration of antioxidant 264 [29, 30].

\section{Experimental}

2.1. Materials and Reagents. Antioxidant 264 (99\% purity) was obtained from Sigma Company (St. Louis, MO, USA). The batch number of the brominated butyl rubber stopper for injection was 16111006 . Novaferon samples (lot numbers: 201708001, 201708002, 201708003, 201708004, 201708005, and 201708006) were provided from Jiehua Biotechnology Group Co., Ltd. (Qingdao, China).

Chromatographic-grade ethanol and dichloromethane were obtained from Dikma Technologies (Beijing, China). Acetonitrile was purchased from ANPEL Laboratory Technologies (Shanghai, China). Deionized water was purchased by China Resources C'estbon Beverage Co., Ltd. (Shenzhen, China).

2.2. Instrumentation. Liquid chromatographic analysis was performed using the Agilent Series HPLC system (Agilent, San Jose, CA, USA) equipped with a diode array detector (DAD). Separations were carried out on an Ultimate XBC18 (150 mm $\times 4.6 \mathrm{~mm}, 5 \mu \mathrm{m}$; Welch, China) analytical column, which was maintained at $35^{\circ} \mathrm{C}$. And the UV detector wavelength of antioxidant 264 was set at $280 \mathrm{~nm}$. Solid phase extraction column and octadecylsilane chemically bonded silica of stuffing were also obtained from Welch. The mobile phase consisted of acetonitrile (A) and $\mathrm{H}_{2} \mathrm{O}(\mathrm{B})(80: 20, \mathrm{v} / \mathrm{v})$. The flow rate and injection volume were set at $1.5 \mathrm{~mL} / \mathrm{min}$ and $20 \mu \mathrm{L}$, respectively. Meanwhile, the condition of flow rate was isometric elution. Liquid chromatographic analysis was used for compatibility experiments.

\subsection{Preparation of the Solution}

2.3.1. Preparation of the Reference Solution. Accurately weighed amount of antioxidant 264 was taken and placed in a $100 \mathrm{~mL}$ volumetric flask; then, the standard stock solution of antioxidant 264 was prepared with anhydrous ethanol at the concentration of $0.4 \mathrm{mg} / \mathrm{mL}$. An amount of the antioxidant 264 standard stork solution to a series of reference substance dilutions contained S1, S2, S3, S4, S5, S6, and S7 and then were diluted by anhydrous ethanol to the antioxiant 264 concentration of $0.004,0.012,0.04,0.08,0.12$, and $0.20 \mathrm{mg} / \mathrm{ml}$. Serial dilutions of the standard stock solution of antioxidant 264 were used for subsequent experimental.

\subsubsection{Preparation of the Test Solution}

(1). Preparation of Samples of the Brominated Butyl Rubber Stopper. The medicinal rubber stopper was shredded, accurately weighed about $2.5 \mathrm{~g}$ in a $100 \mathrm{~mL}$ mill borosilicate glass flask. Subsequently, $10 \mathrm{~mL}$ dichloromethane-ethanol $(1: 1)$ was added accurately, then boiled and refluxed for $4 \mathrm{~h}$, and then cooled down to room temperature with dichloromethane-absolute ethanol $(1: 1)$ added to reduce the amount of loss. Finally, the solution of the brominated butyl rubber stopper was passed through the $0.45 \mu \mathrm{m}$ microporous membrane filter and was used as a test sample.

(2). Novaferon Sample for the Test Solution. Novaferon was filled into the brominated butyl rubber stopper which was used as the sample stopper. Then, $1 \mathrm{~mL}$ Novaferon was extracted by the solid-phase extraction column which was 
activated with $4 \mathrm{~mL}$ methanol and $4 \mathrm{~mL}$ water, respectively. Furthermore, Novaferon was eluted with anhydrous ethanol solution, and the volume was fixed to $5 \mathrm{~mL}$ by anhydrous ethanol solution. Finally, the sample was passed through a $0.22 \mu \mathrm{m}$ membrane filter prior to injection. Novaferon sample was prepared mainly for migration studies.

\section{Results and Discussion}

3.1. Method Validation. The validation study consisted of selectivity, limit of detection (LOD), limit of quantitation (LOQ), precision, repeatability, and recovery, as well as stability.

3.1.1. Specificity. The specificity of the method was proved by comparing typical liquid chromatograms of the blank solution and reference standard solution of antioxidant 264, as well as sample solutions of rubber stoppers and Novaferon. The results showed that there was no interference in the detection of antioxidant 264 in the blank solution, rubber stopper test solution, and Novaferon test solution, and the method presented good specificity and resolution. The chromatograms are shown in Figure 1.

3.1.2. Linearity and Range. The linear solution was injected into the liquid chromatograph with $20 \mu \mathrm{L}$ according to the method described above in Section 2.3.1, and the peak area was determined. The linear regression analysis was carried out with the antioxidant 264 mass concentration $(x)$ as the horizontal coordinate and the peak area $(y)$ as the vertical coordinate. The equation of the calibration curves was as follows: $y=3.23 x+0.9316\left(r^{2}=0.99996\right)$, indicating that antioxidant 264 had a good linear relationship with the peak area in the concentration range of $4.003-200.150 \mu \mathrm{g} / \mathrm{mL}$.

3.1.3. $L O D$ and $L O Q$. The LOD and LOQ were determined at a signal-to-noise ratio of $3: 1$ and $10: 1$ by injecting a series of diluted standard solutions with known concentrations, respectively. When the response values were about 3 and 10fold signal-to-noise ratio, the LOD of antioxidant 264 was $192.2 \mathrm{ng} / \mathrm{mL}$, and the LOQ was $434.0 \mathrm{ng} / \mathrm{mL}$.

3.1.4. Instrument Precision. The precision of the method was obtained by injecting the same reference solution of antioxidant 264 for six times continuously. The results showed that the RSD of the antioxidant 264 peak area was $0.07 \%$, indicating high instrument precision.

3.1.5. Repeatability. Six test solutions of plastic stopper and Novaferon were prepared in parallel. Under the above chromatographic conditions, $20 \mu \mathrm{L}$ of the above solutions was accurately absorbed and injected into the liquid chromatograph, respectively. Then, chromatogram was recorded. The content and RSD of the peak area for antioxidant 264 in six replicates of the rubber stopper sample were $149.76 \mu \mathrm{g} / \mathrm{mL}$ and $0.55 \%$, respectively. As a result, antioxidant 264 was not detected in Novaferon, implying the method has good repeatability.

3.1.6. Recovery. Accurately weighed $2.5 \mathrm{~g}$ medicinal rubber stopper and was cut into small pieces in a $100 \mathrm{~mL}$ mill borosilicate glass flask, parallel operation 3 times, and then added the antioxidant 264 reference substances $0.8 \mathrm{~mL}$, $1 \mathrm{~mL}$, and $1.2 \mathrm{~mL}$, respectively, and then added $10 \mathrm{~mL}$ methyl chloride-ethanol $(1: 1)$ of each sample. Mixture was boiled under a reflux condenser for $4 \mathrm{~h}$ and cooled down to room temperature, supplemented with methylene chlorideethanol $(1: 1)$. Finally, the solution was filtered by the $0.45 \mu \mathrm{m}$ microporous membrane. Each concentration was prepared in 3 copies in parallel.

Three parts of $2 \mathrm{~mL}$ Novaferon, which was filled into the rubber stopper, were added, respectively. Then, the antioxidant 264 standard stock solution $(0.8 \mathrm{~mL}, 1 \mathrm{~mL}$, and $1.2 \mathrm{~mL}$ ) was extracted by the solid-phase extraction column which was activated with $4 \mathrm{~mL}$ methanol and $4 \mathrm{~mL}$ water, respectively. Then, Novaferon was eluted with anhydrous ethanol solution, and the volume was fixed to $10 \mathrm{~mL}$ by anhydrous ethanol solution. Finally, the solution was filtered by the $0.22 \mu \mathrm{m}$ microporous membrane. Each concentration of the sample was prepared in triplicate.

The sample-adding recoveries for antioxidant 264 in samples are shown in Tables 1 and 2. As can be seen from the tables, the average recoveries of antioxidant 264 in the rubber stopper and Novaferon were $97.82 \%$ and $102.19 \%$, respectively. In this section, the regulations of the spike recovery limit for chemical drugs in the 2015 edition of the Pharmacopoeia of the People's Republic of China were referenced, which stated that when the concentration of the analyte was between $1 \mu \mathrm{g} / \mathrm{g}$ and $10 \mu \mathrm{g} / \mathrm{g}, 75 \%-120 \%$ of the recovery was acceptable [31], implying that our analytical method shows high accuracy.

3.1.7. Stability. The reference solution (S4) and the sample solutions of Novaferon and the rubber stopper were used for testing the stability of this method, which were placed for 0,10 , and $22 \mathrm{~h}$ at room temperature, and the results showed that the RSD was $1.86 \%$ for antioxidant 264 in the rubber stopper, and it was not detected in the injection, which indicated that both the test solutions were stable in $22 \mathrm{~h}$.

\subsection{Content Determination}

3.2.1. Extraction of Test Samples. The method of preparation of the rubber stopper for the test solution is the same as the established detection method, and $20 \mu \mathrm{L}$ aliquot of the solution was subjected to the HPLC system for analysis. The result showed that antioxidant 264 was detected in the sample solution of the rubber stopper. The content of antioxidant 264 in the rubber stopper was $0.014 \%$, which met the limit requirement of antioxidant 264 in the European Pharmacopoeia (not more than $0.125 \%$ ). 


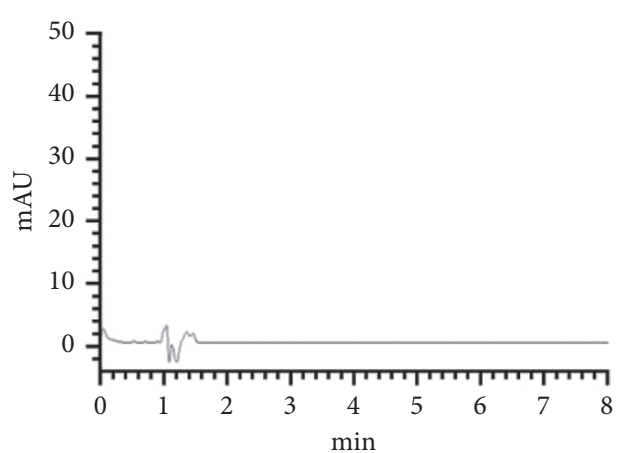

(a)

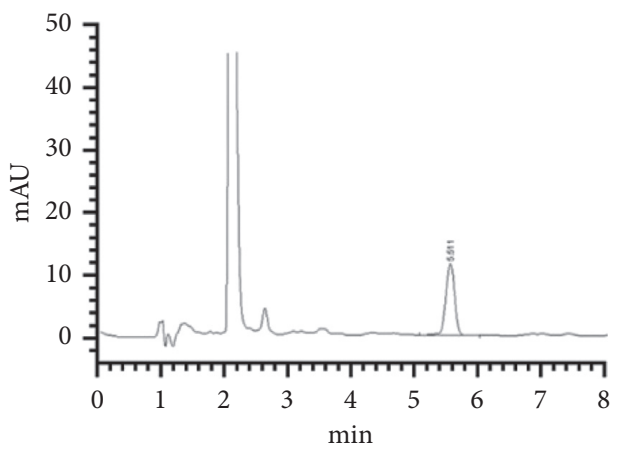

(c)

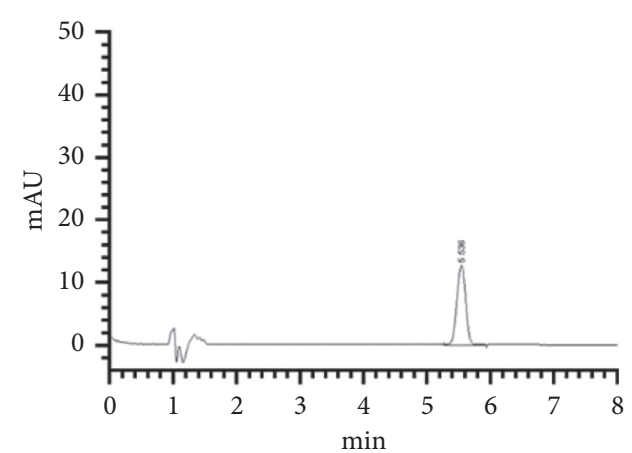

(b)

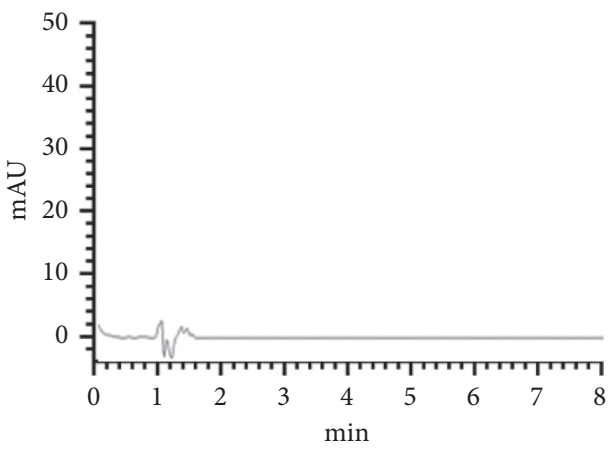

(d)

FIGURE 1: HPLC chromatogram of the blank solvent (a), reference standard solution of antioxidant 264 (b), sample solution of the rubber stopper (c), and recombinant potent antitumor and antivirus protein injection for the test (d).

TABLE 1: Recovery of antioxidant 264 from the rubber stopper.

\begin{tabular}{|c|c|c|c|c|c|c|}
\hline Sample & $m$ sample $/ \mu \mathrm{g}$ & $m$ added $/ \mu \mathrm{g}$ & $m$ found $/ \mu \mathrm{g}$ & Recovery (\%) & Average recovery (\%) & RSD (\%) \\
\hline \multirow{3}{*}{ Antioxidant 264 (1) } & 320.24 & 354.79 & 670.27 & 98.51 & \multirow{9}{*}{97.82} & \multirow{9}{*}{1.56} \\
\hline & 320.40 & 366.11 & 670.27 & 94.93 & & \\
\hline & 320.16 & 360.66 & 670.88 & 96.89 & & \\
\hline \multirow{3}{*}{ Antioxidant 264 (2) } & 400.30 & 346.54 & 744.07 & 99.31 & & \\
\hline & 400.50 & 355.80 & 744.07 & 96.95 & & \\
\hline & 400.20 & 349.91 & 739.82 & 97.43 & & \\
\hline \multirow{3}{*}{ Antioxidant 264 (3) } & 480.36 & 364.79 & 838.82 & 98.68 & & \\
\hline & 480.60 & 367.99 & 837.31 & 97.65 & & \\
\hline & 480.24 & 360.01 & 840.34 & 100.02 & & \\
\hline
\end{tabular}

TABLE 2: Recovery of antioxidant 264 in recombinant potent antitumor and antivirus protein injection.

\begin{tabular}{lcccc}
\hline Sample & $m$ added $/ \mu \mathrm{g}$ & $m$ found $/ \mu \mathrm{g}$ & Recovery $(\%)$ & Average recovery $(\%)$ \\
\hline \multirow{3}{*}{ Antioxidant 264 (1) } & 320.24 & 337.11 & 105.27 & \\
& 320.40 & 336.81 & 105.12 & 105.29 \\
Antioxidant 264 (2) & 320.16 & 337.11 & 100.75 & 102.19 \\
& 400.30 & 403.32 & 100.55 & 2.23 \\
Antioxidant 264 (3) & 400.50 & 402.71 & 100.70 & 100.65 \\
& 400.20 & 403.01 & 100.79 & \\
\hline
\end{tabular}


3.2.2. Migration Test. Migration test was used to detect the migration of antioxidant 264 in the rubber stopper into Novaferon. In this experiment, the migration of antioxidant 264 from the rubber stopper into the product was investigated by the accelerated test $\left(25^{\circ} \mathrm{C} \pm 2{ }^{\circ} \mathrm{C}, \mathrm{RH} 60 \% \pm 10 \%\right)$ for $0,1,2$, and 3 months and long-term stability $\left(2^{\circ} \mathrm{C}-8^{\circ} \mathrm{C}\right)$ for 0 and 3 months.

According to the established detection method, Novaferon was prepared at each time point, and $20 \mu \mathrm{L}$ of Novaferon was absorbed and injected into the liquid chromatograph, respectively. The results showed that antioxidant 264 was not detected in six-batch samples after the accelerated test and three months of the long-term test.

According to the accelerated test and the long-term stability test, the content of antioxidant 264 was not detected in the six-batch samples of Novaferon after storage for a period of time under certain conditions. From a safety point of view, the potential migrant in the injection could be predicted, and the amount of antioxidant 264 was $192.2 \mathrm{ng} / \mathrm{mL}$ on the basis of the limit of detection.

3.3. Migration Assessment. According to the European Chemicals Agency (ECHA) reports of the International Uniform Chemical Information Database (IUCLID), the daily oral intake of antioxidant 264 in humans was $0-0.3 \mathrm{mg} / \mathrm{kg} /$ day. The equation of permitted daily exposure (PDE) for humans is as follows [32-34]:

$$
\begin{aligned}
\text { NOEL } & =\frac{\mathrm{LD}_{50} * 70}{2000}, \\
\mathrm{PDE} & =\frac{\mathrm{NOEL} * W}{F 1 * F 2 * F 3 * F 4 * F 5 * F} .
\end{aligned}
$$

The median lethal dose $\left(\mathrm{LD}_{50}\right)$ value is $6000 \mathrm{mg} / \mathrm{kg} / \mathrm{BW}$ (rat, oral, $24 \mathrm{hr}$ ) for $6000 \mathrm{mg} / \mathrm{kg} / \mathrm{BW}$ antioxidant 264 [35]. The NOEL represents no-observed-effect level, where $W$ represents an arbitrary adult weight of $50 \mathrm{~kg}$ (regardless of sex), $F 1$ represents a factor for extrapolation between species, and $F 1$ equals 5, meaning extrapolation from rats to humans; F2 has a factor of 10 to account for variability between individuals; F3 equals 10, applying to account for toxicity studies of short-term exposure; F4 represents a factor that may be applied in cases of severe toxicity, and F4 equals 1 , meaning serious toxicity is not found to this day; and $F 5$ is a factor that may be applied if the no-effect level is not established $(F 5=1)$, and the composite factor $(F)$ between oral and injection is $100(F=100)$. Therefore, the PDE values of antioxidant 264 are calculated as follows:

$$
\begin{aligned}
\mathrm{NOEL} & =\frac{6000 * 70}{2000}=210 \mathrm{mg} / \mathrm{kg} / \text { day }, \\
\mathrm{PDE} & =\frac{210 * 50}{5 * 10 * 10 * 1 * 1 * 100}=0.21 \mathrm{mg} / \text { day. }
\end{aligned}
$$

The specification of Novaferon was $20 \mu \mathrm{g} / 1.0 \mathrm{~mL} / \mathrm{bottle}$ and $10 \mu \mathrm{g} / 1.0 \mathrm{~mL} /$ bottle of Novaferon, and the dosage of the intramuscular injection was one time/day, $10 \mu \mathrm{g} /$ time. The maximum amount of $20 \mu \mathrm{g} / 1.0 \mathrm{~mL} /$ bottle of Novaferon was
$0.5 \mathrm{~mL}$, and the maximum amount of $10 \mu \mathrm{g} / 1.0 \mathrm{~mL} /$ bottle of Novaferon was $1 \mathrm{~mL}$. As a result, antioxidant 264 was not detected. The maximum daily intake of antioxidant 264 was less than $0.2 \mu \mathrm{g}$. The calculation results showed that the daily intake of antioxidant 264 was lower than the PDE value, and the migration of antioxidant 264 was considered without the safety risk.

\section{Conclusion}

Brominated butyl rubber stopper can be widely used in primary packaging of various drugs. Due to the compatibility issues that may arose in the process of direct contact with drugs, compatibility studies are necessary to ensure the safety, stability, and efficacy of drugs. In this experiment, the content of antioxidant 264 and its migration in Novaferon were determined by HPLC. The method had high precision, good repeatability, high accuracy, and wide applicability.

This method was used to detect one batch of the rubber stopper and six batches of Novaferon. The results showed that the above used brominated butyl rubber stopper contained antioxidant 264, but its content was within the limit of the European Pharmacopoeia. Antioxidant 264 was not detected in six-batch samples, which were stored under accelerated ( $0,1,2$, and 3 months) and long-term conditions (0 and 3 months); meanwhile, the daily intake was lower than the PDE value, indicating that the compatibility between Novaferon and the rubber stopper was good.

The method successfully demonstrated that rubber stoppers used as a drug-packaging material can be assessed during injectable product stability studies, thereby ensuring the safety of the drug.

\section{Data Availability}

The data used to support the findings of this study are included within the article.

\section{Conflicts of Interest}

The authors declare that they have no conflicts of interest.

\section{References}

[1] H. M. Sun, R. Yang, Z. Y. Zhang et al., "The 2015 edition of "Chinese Pharmacopoeia" to enhance the scientific standard system of pharmaceutical excipients and strengthen the quality of chinese medicines," Chinese the Pharmaceutical Journal, vol. 50, pp. 1353-1358, 2015.

[2] Y. Liu, "Current situation and prospect of drug packaging materials and drug compatibility," Tianjin Pharmacy, vol. 25, pp. 56-59, 2013.

[3] B. Xiao, S. K. Gozo, and L. Herz, "Development and validation of HPLC methods for the determination of potential extractables from elastomeric stoppers in the presence of a complex surfactant vehicle used in the preparation of parenteral drug products," Journal of Pharmaceutical and Biomedical Analysis, vol. 43, no. 2, pp. 558-565, 2007.

[4] H. H. Huang, W. R. Tian, and M. C. H. Yan, "The effect of packaging materials for pharmaceutical products on aqueous 
medicine solutions," Journal of Pharmacy Practice, vol. 22, pp. 352-354, 2004.

[5] H. Kim and S. G. Gilbert, "Compatibility of polymeric packaging materials with pharmaceutical products: estimation at migration levels," Packaging Technology and Science, vol. 2, no. 4, pp. 193-200, 1989.

[6] C. C. Corredor, T. A. Haby, J. D. Young et al., "Comprehensive determination of extractables from five different brands of stoppers used for injectable products," PDA Journal of Pharmaceutical Science and Technology, vol. 63, pp. 527536, 2009.

[7] M. X. Guo and Y. H. Liu, "Study on influence of migration of cyclosiloxane compound in rubber stopper on quality of injection," Chinese Journal of Pharmaceutical Analysis, vol. 37, pp. 2112-2116, 2017.

[8] Zh.R. Xue, "Research on the compatibility of medical grade halogenated butyl rubber stopper," Strait Pharmaceutical Journal, vol. 29, pp. 8-10, 2017.

[9] W. H. Zhang, "Study on compatibility of new type compound amino acids injection and packaging materious,"Master thesis, Beijing University of Chemical Technology, pp. 1-107, Beijing, China, 2016.

[10] Y. F. Li, "Study on compatibility of brominated butyl rubber stopper for injection," Changshan Kaijiejian Biopharm Research \& Development (Hebei) Co., Ltd., vol. 4, pp. 340-341, 2017.

[11] S. H. Xu, G. H. Zhang, X. F. Lei et al., "Research Progress on compatibility of drugs and rubber stoppers," Standard Test, vol. 8, pp. 36-40, 2012.

[12] D. Jenka, "Evaluation of the chemical compatibility of plastic contact materials and pharmaceutical products; safety considerations related to extractables and leachable," Journal of Pharmaceutical Sciences, vol. 96, pp. 2566-2581, 2007.

[13] State Administration of Food and Drug Supervision and Administration, "Technical guidelines for compatibility study of chemical injection and plastic packaging materials," http:// www.sda.gov.cn/WS01/CL1616/90946.html.

[14] L. G. Li and Y. L. Zhang, "Brief introduction of medicinal rubber stopper and its compatibility with drugs," Chinese Journal of Pharmaceuticals Industry, vol. 46, pp. 1366-1371, 2015.

[15] D. Zheng, A. Zhou, X. Zhu, H. Zheng, and X. Sun, "An efficient dimethylacetamide-promoted conversion ofAlcohols to alkyl chlorides," Chinese Journal of Organic Chemistry, vol. 36, no. 1, pp. 137-140, 2016.

[16] Z. Fa, C. Alan, and K. Ken, "Structural identification of extractables from rubber closures used for pre-filled semisolid drug applicator by chromatography, mass spectrometry, and organic synthesis," Journal of Pharmaceutical and Biomedical Analysis, vol. 34, pp. 841-849, 2004.

[17] Drug Evaluation Center of the State Administration of Food and Drug Administration, "Technical guidelines for the study of compatibility between chemicals and elastomer seals," http://www.cde.org.Cn/zdyz.do?Method=largePage\&id=252.

[18] C. Corredor, F. P. Tomasella, and J. Young, "Drug interactions with potential rubber closure extractables," Journal of Chromatography A, vol. 1216, no. 1, pp. 43-48, 2009.

[19] YBB00142002-2015, "Guiding principles for testing the compatibility of drug packaging materials with drugs," $\mathrm{Na}$ tional Drug Package Materials Standard, p. 381, 2015.

[20] X. M. Huo, Y. N. Ma, and Y. Jiang, "Selection principles and evaluation points of packaging materials and containers for direct contact injections," The Chinese Journal of Clinical Pharmacology, vol. 28, pp. 797-800, 2012.
[21] L. Cheng and J. Su, "Measurement of cresol, 2, 4-phenol and 264 contents in antioxidant by capillary gas chromatography," Applied Chemical Industry, vol. 36, pp. 1247-1254, 2007.

[22] Y. Jiang and F. J. Cheng, "Determination of anti-oxidants and migration in chlorinated butyl rubber stopper for injection," Heilongjiang Medical Journal, vol. 29, pp. 436-439, 2016.

[23] J. Zhou, G. Yin, H. W. Liu et al., "Determination of BHT in medicinal butyl rubber plug by GC-MS/MS method," Chinese Journal of Pharmaceuticals, vol. 44, pp. 801-803, 2013.

[24] X. Zhao, Study on the Compatibility Between Butyl Rubber Closures and Ceftriaxone Sodium, Peking Union Medical College, Beijing, China, 2006.

[25] European Pharmacopoeia Commission, European Pharmacopoeia 7.0 2011, European Pharmacopoeia Commission, Strasbourg, France.

[26] H. Y. Wang, Y. F. Zhang, and J. Y. Ying, "Detection of antioxidant 264 content in butadiene rubber by extraction-gas chromatography," The Science and Technology of Rubber, vol. 11, p. 42, 2013.

[27] X. W. Pu, P. Cui, J. Wu et al., "Migration studies on the common antioxidants in rubber plug," Chinese Journal of Pharmaceutical Analysis, vol. 36, pp. 2231-2240, 2016.

[28] M. Li, D. N. Pei, L. Tao et al., "Analysis of the primary structure of recombinant potent anti-tumor and anti-viral protein by liquid-quality spectrometry," Chinese Journal of Biology, vol. 24, pp. 1473-1476, 2011.

[29] J. Feng, X. Y. Cai, and Y. Liu, "Determination of antioxidantBHT and vulcanizing agent extractable sulphur in medicinal butyl rubber," Chinese Journal of Pharmaceutical Analysis, vol. 37, pp. 702-706, 2017.

[30] Y. Jiang, Y. N. Ma, X. M. Huo et al., "Technical guiding principles for the study of compatibility between chemical injection and plastic and special packaging materials interpretation of an extraction and migration test method design," Chinese Journal of New Drugs, vol. 23, pp. 940-943, 2014.

[31] Chinese Pharmacopoeia Commission, Pharmacopoeia of the People's Republic of China, Chemical Industry Press, Shanghai, China, 2015.

[32] E. L. Barle, J. C. Bizec, M. Glogovac et al., "Determination and application of the permitted daily exposure (PDE) for topical ocular drugs in multipurpose manufacturing facilities," Pharmaceutical Development and Technology, vol. 23, no. 3, pp. 225-230, 2017.

[33] L. Müller and E. Gocke, "Considerations regarding a permitted daily exposure calculation for ethyl methanesulfonate," Toxicology Letters, vol. 190, no. 3, pp. 330-332, 2009.

[34] P. Parris, J. N. Duncan, A. Fleetwood, and W. P. Beierschmitt, "Calculation of a permitted daily exposure value for the solvent 2-methyltetrahydrofuran," Regulatory Toxicology and Pharmacology, vol. 87, pp. 54-63, 2017.

[35] European Chemicals Agency (ECHA), "Registered substances, 2,6-di-tert-butyl-p-cresol (CAS Number: 128-37-0) (EC Number: 204-881-4)," 2016, http://echa.europa.eu. 